\title{
'I will not leave, my freedom is more precious than my blood' From affect to precarity: crowd-sourced citizen archives as memories of the Syrian war
}

\author{
Dima Saber and Paul Long
}

School of Media, Birmingham City University, Birmingham, UK

\begin{abstract}
Based on the authors' mapping of citizen-generated footage from Daraa, the city where the Syria uprising started in March 2011, this article looks at the relation between crowd-sourced archives and processes of history making in times of war. It describes the 'migrant journey' of the Daraa archive, from an eyewitness documentation of the early days of the uprising, to a digital archive of the Syrian war. It also assesses the effects of digital technologies for rethinking the ways in which our societies bear witness and remember. By so doing, this article attempts to address the pitfalls attending the representation and narrativisation of an ongoing conflict; from issues of ownership, consent, harm, agency, vulnerability, and objectification, to the broader ethical implications of representing death, trauma and the affective experiences of war. It concludes with a reflection on the changing nature of such archival materials, mainly in the light of rising concerns of the precariousness and disappearance of the digital archives.
\end{abstract}

Keywords: Syrian war; Daraa; archive; citizen-generated footage; ethics; affect.

\section{Introduction}

Seven digital files presented in a Dropbox folder: they might be orphan pieces as there is no information concerning from whence they came or where they belong. 
A first video is titled 'Yadan, a one-man protest.mp4' and is 46.8MB. Double click the first file and the MAC protests with a pop-up: 'The document 'Yadan, a one-man protest.mp4' could not be opened.' It advises that 'The file may be damaged or may not be a movie file that is compatible with QuickTime Player.' Via VLC media player ('free and open source media player, encoder, and streamer), the first file opens and over 1'47" shows a sunny day: a man walks the streets of what might be an Arab, Middle Eastern town. While there are 'voices off', the streets are deserted and scattered with broken masonry: walls are pockmarked with what appear to be bullet holes. The man holds a homemade sign above his head. In Arabic script it reads 'No matter how much you bomb, I will not leave, my freedom is more precious than my blood 12/7/2012 The destroyed neighbourhood of Tariq el-Sed'. The only other figure in the film is the cameraperson, whose shadow is caught in the frame at one point holding what is most likely a mobile phone - also signalled by a handheld wobble on the image and by its digital clarity. The film concludes by a street corner showing a spray-painted image of the Free Syrian Army flag.
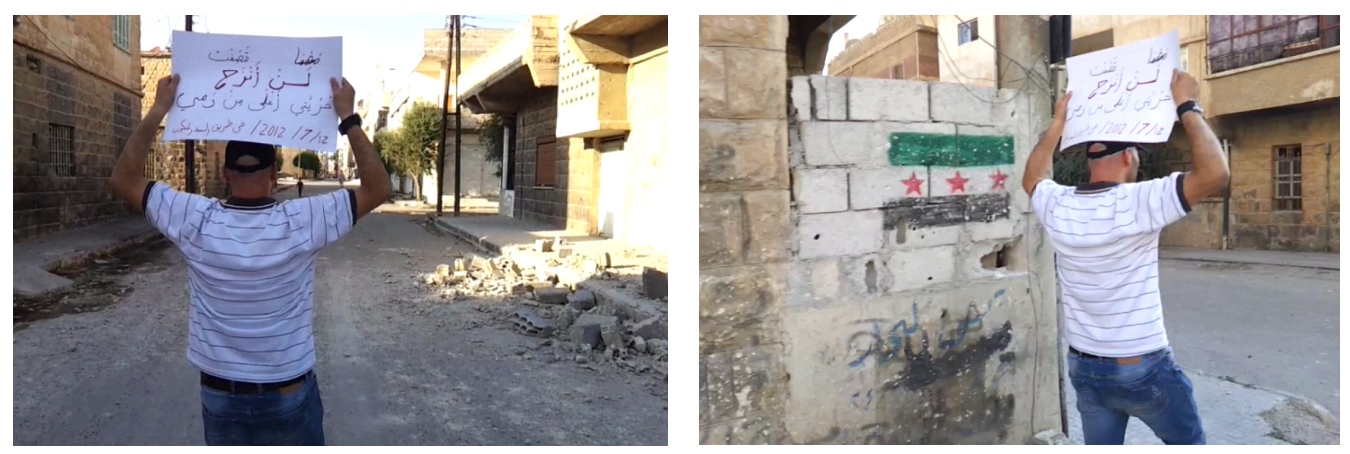

Figure 1: 'Yadan, a one-man protest', screenshots by the authors

What are these 'films'? In fact, are they films at all? Who made them? Where do they come from? Who is Yadan, and where is 'Tariq el-Sed' neighbourhood? How did they come to the authors' attention and why should we attend to them? What have they to say to issues of archives and records, and the impact of the digital?

As we explain in more detail below, these sequences were shot in Daraa, the city where the Syrian uprising began in 2011. They document the first 18 months of the Syrian revolution as it turned from a non-violent movement, to a militarised and Islamised conflict that became a deadly civil war. Based on the authors' mapping of this 
citizen-generated footage from Syria, and on interviews with Syrian activist Yadan Drajy, who shot this material with four of his activist friends between March 2011 and August 2012, this article explores the relation between crowd-sourced archives and processes of history making in times of war. We start with a description of the 'migrant journey' of the Daraa archive, from an eyewitness documentation of the early days of the uprising in Syria, to a collection of digital files in the Dropbox folder of two researchers in the UK. Then, we assess the effects of digital technologies, and of the democratization of image production and dissemination for rethinking the ways in which our societies bear witness. By so doing, we attempt to address the pitfalls attending the representation and narrativisation of an ongoing conflict from a fragmented, citizen-generated archive; from issues of ownership, consent, harm, agency, vulnerability, and objectification, to the broader ethical implications of representing death, trauma and the affective experiences of war. Finally, we conclude with a reflection on the changing nature of such archival materials, mainly in the light of rising concerns of the precariousness and disappearance of digital archives.

\section{From crowd-sourced witness to refugee: the migrant story of the Daraa archive}

'The declaration of the revolution.m4v' is less than a minute long. A preacher, lifted on the shoulders of two men, is speaking into a megaphone: 'We were hoping that no blood would be shed, except in our war with the enemies of God, and with our enemies the Zionists. But what's been done is done, and it's all the will of God. So be patient and be calm. God is Great, God is Great...' The crowd then rumbles in one unified voice: 'Revolution, revolution, revolution'. Five times, ten times, twenty times. We understand from the title of the file that this moment marks the first public declaration of the Syrian revolution in March 2011. 


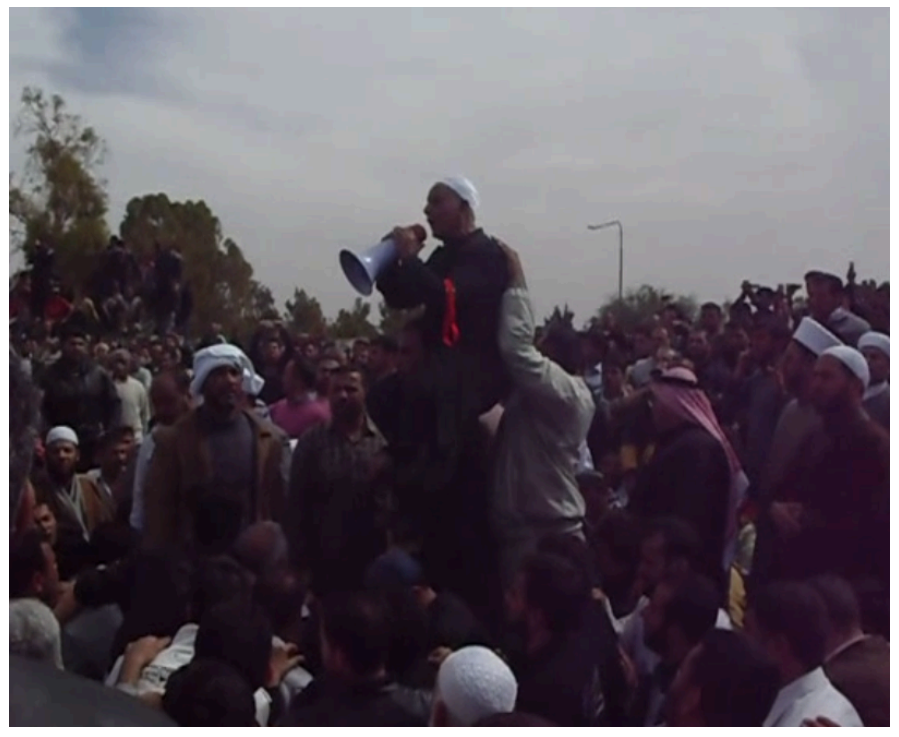

Figure 2: 'The declaration of the revolution', screenshot by the authors

In September 2012, Syrian activist Yadan Draji crossed the Syrian-Jordanian border on foot, carrying a hard drive containing footage that he and four friends shot in Daraa, the city where the protests first erupted in 2011. In 2013, he entrusted his hard drive to two filmmakers, Rami Farah and Liana Saleh, one of the present authors, and producer Signe Byrge Sørensen to use this archive in the making of a film that depicts media representations of the Syrian war. A copy of the Daraa archive made its way to the Birmingham Centre for Media and Cultural Research where this article's authors are both based.

Comprising hundreds of hours of live recordings of protests, activist gatherings, bomb attacks, funerals and testimonies, the hard-drive formed the point of departure of a ninety-minute documentary film which is now in production phase and is scheduled for release by the end of 2017. Shot by activists who were mostly operating anonymously in tense and dangerous conflict-affected areas, and with very limited access to the Internet or to video technology, the material was recorded using different 
devices (smart phones and DV cameras including mini dvs and handycams, etc.), and in multiple formats (such as .mp4, .mov, .MTS, .MPG, .3gp, .AVI, .flv, among others). The material comprises 12756 video sequences, totalling over 2TB, of which 3482 are 'unique' videos of varying lengths and sizes, and of an estimated duration of 400 hours.

For the purpose of this article, we have compiled a selection of seven videos from the Daraa archive, which we use as a structuring framework for our exploration of the relation between citizen-generated archives and history making in times of war. It is worth noting in this regard that a bigger sample of 2000 videos will be made available online by 2017 through an open-access database, as part of a research project one of the present authors is currently developing with film and technology partners based in Denmark and in Berlin.

\section{Defining the archive}

In a keynote speech at the Museum of Contemporary Art in Barcelona in 2012, Ernst Wolfgang said that 'What in public discourse [...] is frequently called the 'archive' turns out to be, in most cases, a most imprecise metaphor for all sorts of collections and memory. ${ }^{1}$

It seems, then, that a possible good point of departure for our work on the Daraa material is a reflection on how we should name it.

A collection? Perhaps an 'archive in the making'? - Not formed, but in transition; seeking roots, but founded in an origin of trauma and displacement? Or 
maybe a 'migrant archive'? - Seeking fixity and a nation state, like the activists who shot it, but with a history to speak for?

In asking 'What good are the archives', Elizabeth Shepherd says that: 'Archives have the potential to change people's lives, ${ }^{2}$. She writes:

\footnotetext{
'Is an archive, an archive, simply 'if I think it is' or is it possible for experts (archivists, perhaps) to determine positively or contingently what is an archive and what is not? In the past, archivists have sometimes been keen to decide what's in and what's not: that oral history or a photographic collection does not constitute an archive, that community archives fall outside the definition, that only appraisal by a professional archivist can determine 'archival value', that email could not be a record. ${ }^{3}$
}

Yadan Drajy has always thought of his material as an 'archive'; when asked in an interview in 2016 how he refers to it he said: 'The Daraa archive? An archive, of course... I've always called it that. I wasn't the only one doing it, but we were all archiving for two publics; other Syrian revolutionaries in other cities who, like us, were taking on the streets, and an international public opinion who needed to know what was happening in Syria., ${ }^{4}$ But when asked whether he thought of himself, and of his fellow activists, as archivists, his answer was less forceful: 'Me? An archivist? Oh, I don't know, that, you should tell me. Am I?'5

So does a citizen-generated sequence of the first public declaration of the Syrian uprising constitute part of an archive? Who gets to decide? And is it enough that its author sees it as such, for us to accept the definition and consider the Daraa material as a new social memory of the war; a citizen-generated repository that documents the unfolding events of the Syrian conflict? 
Important here are both the general issues around the archive, its definition and impact, and the specificity of this material and its meaning. In its collective production, process of collation, travel and the duration of its transmutation from live witness to historical material, awaiting engagement and use, is a challenge for its hitherto impotent impact. What originated in an impromptu mode of citizen journalism, generating a potential resource for conventional media reportage of events, in a short period has become an imperilled and invaluable collection of material. It pays witness to events and could potentially aid an understanding of the origins of the Syrian war, and hold to account those parties whose violence and impact is represented therein.

In an attempt to resolve this naming issue, we suggest turning towards its definition in The Archaeology of Knowledge. If 'History', as presented to us by Michel Foucault, does not look at the documents of the past as a dusty, barely decipherable, silent mass, it's because he does not see the 'Archive' as a compilation of items of a completed past. Subsequently, the archive becomes considerably more than a simple series of marks made by humans and confined in the dusty silence of libraries; it is no longer what has been said, but the rules that govern the emergence of discourses as particular events. In his definition of the 'archive' Foucault writes:

'By this term I do not mean the sum of all the texts that a culture has kept upon its person as documents attesting to its own past, or as evidence of a continuing identity; nor do I mean the institutions, which, in a given society make it possible to record and preserve those discourses that one wishes to remember or keep in circulation. [...] The archive is first the law of what can be said, the system that governs the appearance of statements as unique events. [It] is also that which determines that all these things said do not accumulate endlessly in an amorphous mass, nor are they inscribed in an unbroken linearity, nor do they disappear at the mercy of chance external accidents [...]. [The archive is not] that which collects the dust of statements that have become inert once more, and which may make 
possible the miracle of their resurrection; it is that which defines the mode of occurrence of the statement-thing. ${ }^{6}$

What is useful to us in this Foucauldian definition is that it acknowledges the 'messiness' of our Daraa material as a constituent of the nature of the archive itself; although it is collated by citizen journalists who do not work for 'recognised' media institutions, and although it is non-linear and fragmented, the fact that it is the 'unique' statement of five activists who have witnessed an important moment is enough reason to consider it an archive. The Daraa archive is, in that sense, an object of the present, although it documents events, people and places of the past. As it continues to exist in the present, it summons us to dismantle it and then reconstruct it, to work it up, inspect it and interpret it in order to make sense of it, and of the events it depicts. And this is, in one way, one of the aims of this article.

\section{A crowd-sourced witness}

When asked about his source of inspiration to take to the streets in March 2011, Drajy said: 'The long years of oppression in Syria. The protests in Tunisia and Egypt and the coverage it all got on global media such as Al-Jazeera of course encouraged some, but Syrians had already lost patience and were striving for freedom and social justice. The people were ready, the country was ready and we were witnessing a historic moment. So of course, we took to the streets ${ }^{, 7}$. And when asked about his motivation, he said he understood very quickly that he was witnessing 'a very important and historic moment', and wanted to 'document this moment in the history' of his people and his country. 
With Reinhart Koselleck's 'space of experience' and 'horizon of expectation' in mind, we asked him: 'So was it the present moment that you were living that mattered the most?'

\footnotetext{
'At the beginning, yes... I needed to record exactly what was happening. Then, when the shelling started, I realised that some people will die, and some places will no longer exist, so I found myself in between two moments, the present and the future. I started shooting for history... History? Maybe this is the right thing to say, or the future? I'm not sure. But I was documenting so that a few years from now, we would be able to say this is how it all started, this is what happened in Daraa. ${ }^{9}$
}

It is apparent then, that the moment Yadan Drajy and other activists started documenting the Syrian uprising the material that wended its way into the Daraa archive was not necessarily captured with intention or anticipation of preservation. Paul Frosh and Amit Pinchevski ${ }^{10}$ note that every claim to witness involves a form of mediation, while every mediation is a mode of witness. We can then infer that the primary motivation in recording the events in Daraa was not accidental, but purposeful - it was to say 'This is happening now: like this, to us!' Such an intolerable situation demands a response and the moral economy of contemporary vicarious witness afforded by mass media and the ubiquity of social media means that it is no longer possible to claim ignorance of events. As such, the Daraa record underlines the immediacy with which a response was needed.

As the non-violent protests slowly turned into a vicious civil war, Drajy and his fellow activists, like many other citizens in possession of mobile phones with camera technology, began to understand the unfolding of events around them; their intentions in documenting these events also changed. Eventually, they realised that the value of their 
footage is not necessarily confined to the present 'historic' moment they were witnessing, but could potentially serve as a repository of shared memory of the people and places obliterated by the viciousness of the war.

As such, the regular mode of media witness is from the perspective of authority. In conflict zones, mainstream reporters speak about events recorded by cameras that are often placed behind the lines of police or infantry for instance. With a frisson of risk, they look out onto 'insurgents', 'protestors', 'citizens', 'crowds' from a position where their individual safety - and that of the image, sound and account - is guaranteed and their objectivity perhaps, is inflected by authority, a rule of law. Andén-Papadopoulos notes that a common critique of professional mainstream journalism concerns 'its limited and inadequate exposure of distant suffering in ways that tend to trivialize the victim's experience, ${ }^{, 11}$. The rise of new information and communication technologies allowed for the incorporation of crowd-sourced footage into crisis reporting, as a way to counter skepticism towards the ability of global media to construct 'a moral imaginary and memory of the pain of others', thus adding to the authenticity, and thereby the moralizing force of the very act of witnessing.

It is clear in the case of the Daraa archive that this material was gathered in the face of incredible risk, record and testimony produced out of great commitment. As Paul Ricoeur notes in another context:

'The witness is capable of suffering or dying for what he believes. When the test of conviction becomes the price of life, the witness changes his name; he is called a martyr., 12 
In addition to constituting a record of the events in March 2011, the creation and journey of the Daraa archive also document the journey of the activists who shot the footage itself, as they first went out in peaceful protests, then got quickly trapped in the violence of the war: two of them were killed by snipers, two are now refugees in Jordan and Turkey, and one has taken up arms and is still fighting in Daraa.

Here then one can appreciate this archive as imbued with a quality derived from Avishai Margalit's formulation of moral witness, derived from the presentness of its creators to the events it captures and the threat that is apparent in that capture: 'The moral witness should himself be at personal risk, whether he is a sufferer or just an observer of the suffering that comes from evil-doing. ${ }^{13}$ While Paul Frosh and Amit Pinchevski ${ }^{14}$ appropriate Margalit's ideas on memory with caution to deal with witness, this is apposite for conceptualizing the collective weight of the Daraa Archive. To conceptualise a moral quality in this material is to not pre-emptively interpret the archive material in terms of the account of one side or another, but to take at face value its representation of a crime, and of a people's vulnerability.

\section{The affective dimension of the archive}

Two other digital files in the same Dropbox folder, their titles make one wary of opening them: 'DIY morgue.mp4' and 'Lynn funeral.mp4'. The first film opens with a sound of dripping water, but one quickly understands it is actually the sound of dripping blood, from the red buckets on the floor. 3'12" of Yadan Drajy filming in a DIY morgue; wooden boxes containing dead bodies, and plastic bottles filled with ice thrown on top of them. He zooms every now and then on the faces of the dead, and says their name. He explains they've been unable to bury their dead because of the intense shelling. 
'Lynn funeral.mp4' is even more unbearable to watch - or analyse - especially that the same Daraa hard-drive included, under another folder titled 'Lynn', pictures and videos of the 9 year old girl when she was still alive, dancing in a brand new dress. It is with those pictures in mind, that one watches her funeral. The video opens with a closeup on the body of small girl, all except her small face wrapped in white linen. Leaning over her is a mourning woman in black, who we later understand to be her mother. 'Lynn's funeral.mp4' is over half an hour of a mourning mother, speaking in a quiet, barely audible voice, to her dead child. She tells her about the playgrounds that awaits her in heaven, apologizes for not buying her the dress she wanted for Eid, and promises to join her there soon; thirty minutes that seem to last an eternity.
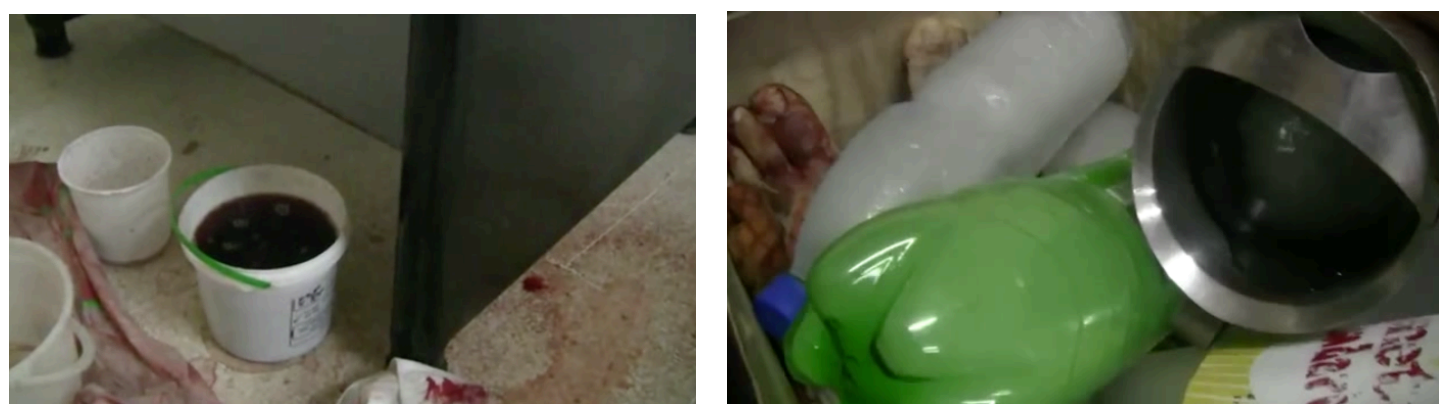

Figure 3: 'DIY morgue', screenshots by the authors

In considering the relation between bearing witness and what she referred to as 'the crowd-sourced video revolution', Andén-Papadopoulos notes that as opposed to the 'model of detachment' global media outlets are often criticised for, citizen-generated images 'summon an affective and embodied experience from 'inside' the event that is believed to impose a particular moral and political obligation on the consumers of news. ${ }^{15}$ This moral obligation is often contingent on what she calls the 'affective gaze of the citizen videographer', one that can ignore the standard prescriptions of mainstream gatekeeping, especially in terms of content warnings; at no point does the Daraa archive warn us that the material that follows contains graphic scenes that may be disturbing to some, at no point is viewers' discretion advised. 
The double weighted tragedy here is bound up in the moment it represents, the opportunity such an archive makes to understand it and the challenge it presents in so doing; that this is an archive and a collection not of 'dispatches from the frontline' with the immediacy of news, but material that is now becoming relegated to history. In that sense, the archive always attests to a mode of forgetting. And it is probably that fear, of the dead being forgotten, that also motivated Drajy and his fellow activists to capture, in infinite and intolerable close-ups, the horror of the unfolding Syrian war.

\section{Affect, trauma and respect}

Farge writes: 'It is, of course, the surplus of life that floods the archive and provokes the reader, intensely and unconsciously. The archive is an excess of meaning, where the reader experiences beauty, amazement, and a certain affective tremor. ${ }^{16}$ Shot by activists who wanted to "expose to the world the horror and violence of the Syrian regime ${ }^{17}$, there is little beauty in the Daraa material, and a lot of tremor.

Although its excessive violence might seem overwhelming, and at times unintelligible, one must seek to extract meaning from the fragmented narratives depicted in the Daraa archive, in as way to understand how the Syrian revolution began as a hopeful wave of non-violent protests and turned into one of the deadliest conflicts in our modern history. As Farge notes, 'emotion is another tool with which to split the rock of the past, of silence.' 18

We argue that in order to do so - extract meaning from the obscure chaos of war - one needs to take into account the pitfalls attending representation and narrativisation, especially when performed in the Western academy, and given the reality of the war's human, cultural heritage and socio-economic losses. From issues of ownership, consent, 
harm, participation, vulnerability, subjectivity and objectification, neo-colonialism and geopolitics, to security, agency and responsibility; when working with material such as the Daraa archive, shot by and of people who died, or are still in Syria, it is vital to protect identity, sustain objectivity, avoid objectification, respond to vulnerability, and limit harm, etc. It is with these considerations in mind that we decided, for example, not to include a screenshot of Lynn's funeral video in the introduction to this section.

Caswell, Cifor and Ramirez define affect as 'those visceral forces beneath and alongside, feeling and emotion, encompassing the conscious, the semiconscious, and that which is other than conscious knowing. ${ }^{, 19}$ They note that affect speaks not only to the trauma captured and documented in the archive content, but in the materiality, the institution of the archive itself. In that sense, and in the case of the Daraa material, to think of affect is to think of questions related to the political economy of the archive itself; what is the cost of doing and/or preserving something? What is the cost of not doing something, or not showing/using graphic images from the Daraa material? Who will use this archive and how? In the end, a political economy of the digital archive also asks: who owns it?

Thinking about affect highlights both the dimensions of content and form. Here, Daraa's trauma may be present in film but there is also something to be considered about the anxiety, commitment and fears of the digital files themselves. What went into their generation, collection and preservation? This last is a narrative of escape and a call for someone to attend to this testimony. 
What comes out of our first round of mapping of the Daraa archive is that issues of ownership and authorship are inherent to the evolving nature of the citizen-generated archives as made available by digital technologies; operating in conflict areas and under authoritarian rule, archivists needed to stay anonymous to preserve their identity and security. Five years later, and as most Syrian activists and archivists found themselves scattered as refugees across the Arab region and the world, they've come back to claim authorship over their collective, anonymously-produced digital archive. This shift from what we call an 'imposed anonymity' to a 'claimed ownership' speaks to the very fluid nature of these digital archives, whereby the rules underpinning the political economy of the digital are both reflected in, and affected by the changing contexts in which these archives are produced and disseminated. As most of them have been forced to leave Syria, and as armed conflict slowly made impossible all forms of non-violent protest, the activist/archivists were only left with the much needed accreditation of having once witnessed that moment, of having been part of something really significant, and of having contributed to it: 'I shot this! This is me, I was there!'

In that sense, our Daraa archive might have a family resemblance to the concept of 'community archives' as defined by Caswell, Cifor, and Ramirez:

'[...] The term 'community archives' is a general umbrella term under which a host of different types of projects may fit. Community archives can range from entirely independent, permanent, non-profit organizations dedicated solely to archival endeavors; to archival projects within larger community organizations; to informal, loosely defined, temporary configurations of community members dedicated to shaping the collective memory of a community's past. As such, the term 'community archives' can be seen as being imposed externally by archival studies scholars rather than emerging organically from within such community efforts. ${ }^{20}$ 
We can pursue ideas of affect here in order to understand what is invested in the preservation and anxiety about purpose, sustainability, ownership (possession), kinship/proxy, duty etc., as well as the interpretation and use of the archive itself - that it has to be done with respect, and bear witness to those who bore witness as represented here.

The other reason why 'community archives' could potentially serve as a useful framework to analyse the narratives depicted in the Daraa archive is the fact that its authors connect it to the concept of 'symbolic annihilation', 'a term media studies scholars use to describe the ways in which mainstream media ignores, misrepresents, or maligns minoritized groups. ${ }^{21}$ This concept is quite similar to what AndénPapadopoulos refers to as 'the model of detachment of global media outlets', and which citizen-generated footage offers a counter-narrative to, as we described above. As such, another main motivation behind Yadan Drajy and his fellow activists using their mobile phones to document the early days of the uprising was an 'obsession' with what he called 'the truth': 'I had a problem with what was said on the official Syrian TV and on other media channels, and with what wasn't said about us, and about our martyrs. Their reports disregarded our struggles and our dead... We all felt we had a duty towards our country and our people to tell the truth... To tell our own story and our own version of what was really happening on the ground in Daraa. ${ }^{, 22}$

Caswell, Cifor, and Ramirez's aim is to extend this concept of 'symbolic annihilation' to understanding absence in the archive, and in particular assessing the impact and value of community archives of groups marginalized in the archive, posing a notion of 'representational belonging' for such enterprises, which offer spaces of 
recognition, memory and so on. As such, they consider that these archives empower communities to create their own histories; in that sense, they have epistemological ('epistemology or the theory of how we know what we know') and ontological ('ontology or the study of the nature of being') effects:

\begin{abstract}
'On an epistemological level, community archives provide empirical evidence for a community to assert its existence [...] By collecting materials that document the previously unknown history of a community, a community archive asserts that we were here $[\ldots]$. On an ontological level, a community archive affirms that I am here. It reflects and asserts identities in the present, allowing individuals 'to suddenly see themselves existing' in ways they previously could not and did not. ${ }^{23}$
\end{abstract}

Particularly useful here is Ariella Azoulay's reading of Derrida's Archive Fever, which she quite rightly describes as a 'problematic translation' of the French Mal d'Archive. Based on Derrida's description of the three pylons supporting the archive the first one is the archon, the sentry, 'guardian of the documents', and the other two are the place and the law, 24 - we can potentially see Yadan and his four friends as the 'new' archons of the Daraa archive; they replaced the traditional 'guardians of documents' who have, for a long time, prevented the outbreak of the 'archive fever'. They replaced those who 'were put in charge not only of preserving documents, $[\ldots]$ but of distancing those wishing to enter the archive too early, before the materials stored within would become history, dead matter, the past. ${ }^{, 25}$ By so doing, they also democratised the archive, and transformed the Daraa material from a trace of the past, to an object of the present.

These 'new' archons were ignored by Derrida, probably because their counternarratives were only made possible by the affordances of new technologies, thus 
contesting the monopoly of 'official archival agents and institutions'. In this context Azoulay writes:

'Withheld rage, suffocation, nausea, anger, frustration, fright, horror and helplessness, no less than the hope of or passion reported by those infected with archive fever, bear witness to the fact that archive documents are not merely a collection of dead letters. They are not items of a completed past, but rather active elements of a present. They must be properly and carefully handled, precisely because they are the means by which destruction might continue to be wrought just as they might enable some restitution of that which continues to exist as present, in the present. ${ }^{26}$

One can of course read in this definition the resonances of the Foucauldian approach to History and the Archives, as we described it earlier in this article.

In summary, our mapping of the Daraa material suggests that any analysis of the affective dimension of war archives needs to first take into account the emotions of those who created them. Cifor and Gilililand's summary of the affective turn in archival work is particularly useful in this context, as they ask: 'what are the affects for individuals, communities and nations of the absence or irrecoverability of records? In what ways, and to what extent, do records, and the holdings of our archives capture or contain emotions and other forms of affect that were experienced by the creators or others engaged or present in the making of the records? ${ }^{27}$

Therefore, what should matter first to anyone looking into citizen-generated archives of the current Syrian conflict are the feelings and emotions that motivated activists to become archivists and document their daily war diaries. 
Then, further questions about the affective dimension of the archive should also relate to its potential users, of how affects might be represented and their impact responded to; what ethical implications should one take into account when considering the affective dimensions of citizen-led archival practices? And how could affective considerations be incorporated in the theory and practice of representing conflict 'ethically' and 'truthfully'? This last point raises questions about the very nature of the archive, its status and boundaries.

\section{'Archiveness' vs. precariousness}

'Daraa el-balad.mp4' is over half an hour long. 'El-Balad' is Arabic for country, or 'city centre'. The latter is probably meant through the title. The camera is positioned somewhere on the front seat, next to the driver. We are in a car, and the car is moving around the city. We don't see the person driving, nor do we hear him speak. The only audible sound is of the engine of the moving car. He's driving slowly, taking short cuts, cul-de-sacs then turning around, one highway on two occasions; he drives past a mosque, a graveyard, and a street with closed shops. The camera films the city as he takes us on a tour around Daraa. In one sequence we see kids playing football in the middle of the street; he has to wait for them to move away so he can drive past them. Apart from the children, and a few people here and there, the streets are mainly deserted. There are many checkpoints, and a heavy presence of army men on almost every roundabout. He drives too close to a tank, and you can't help but worry about the hidden camera; what if they see it? Is he supposed to be filming at all? Is the camera actually hidden, or is someone holding it? At one point, a hand signals the presence of someone else in the car. Rubble on both sides of the streets suggests earlier clashes, but it seems the streets are being cleared after what appears to be localised violence. But there is something in this video that inspires fear, the city is too quiet, too empty, something that looks and sounds like the quiet before a crazy storm.
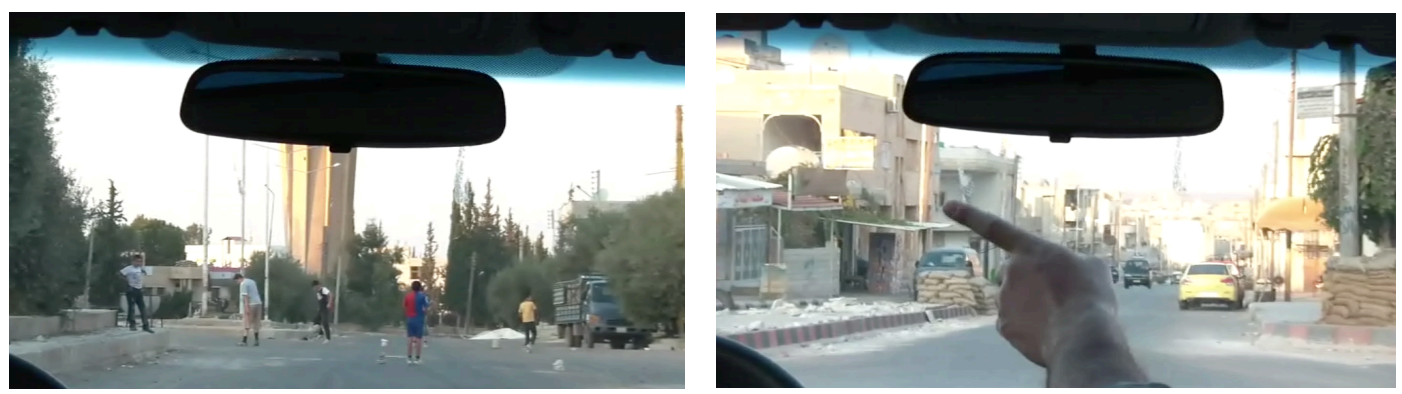


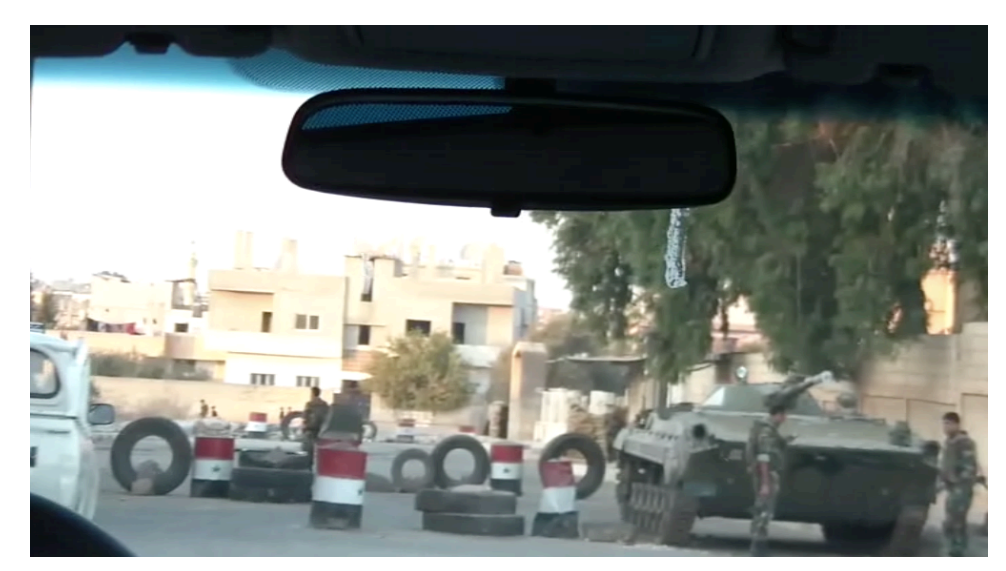

Figure 4: 'Daraa el-Balad', screenshots by the authors

Another video entitled 'Preparation for Daraa tour.mp4' gives context to the first video. It is short and quite straightforward; we see Yadan hiding a camera in a napkin boxwe now understand where the camera was hidden in the previous film-and his mother, or grandmother, in the living room with him, asking him to be careful. We understand he was preparing to go on a street documentation of the city centre of Daraa.

\section{Archive and nostalgia}

When asked whether he ever watches again any of the footage he shot back in 2011 and 2012, Yadan Drajy said he often goes back to the 'Daraa el-Balad' film: 'Every time I see it, I discover new things; I ask myself whose bakery is this, I wonder about the names of the shops on the street banners, I remember things that I thought I had forgotten. I wanted to document the city and the streets and the shops because I knew they might not be there in a few years time. And here we are. This video is in my opinion one of the most important videos I shot in Daraa. ${ }^{28}$

Tragically, what this archive conveys is what was lost: the destruction of Daraa, the loss of so many lives, and the flight of a population. Importantly however it can be thought of as capturing why people thought it was worth protesting in the first place, 
and why it was worth documenting the changing faces of the city, of its people and its protests. As inferred from the description of the Daraa films at the outset of this article, filming was a purposeful act, and there was a consciousness about the way in which the camera is used, and the way in which even a short sequence is organised.

As the 'Daraa el-Balad' film attests, the archive does not only feature endless instances of conflict, death or drama. On the contrary, its variety is what gives it its power: visceral scenes of war alongside sequences that document the changing faces of the city and its inhabitants; scenes of children's funerals, alongside scenes of other children playing football despite the destruction and the war. What this archive also does is serve as a living memory of the moments, people and places that might disappear, and be forgotten.

In 'What We Left Unfinished. The Artist and the Archive', Marian Ghani reflects on the changing materiality of the archive in Afghanistan, how it decays, gets displayed and re-organized to a degree in which its meanings change in changing contexts and times and uses. This observation is useful in highlighting how the archive contains traces of previous iterations, 'past selves it shed on the way to becoming the present archive. ${ }^{29}$ Nonetheless, she notes that the indexing of the archive is critical, because metadata is our first gateway through every archive. In that sense, we see in the titles that Yadan Drajy has given the Daraa videos, the ways in which he organised the footage in different folders and subfolders, giving each folder a name, as a first layer of metadata. Shot with a number of devices over a period of 18 months, the Daraa digital files have all preserved the dates on which they were recorded, and details of their original formats; this is another layer of metadata that we have explored in our mapping 
of the archive. This metadata is particularly precious as it allowed us to reconstruct the chronological sequence of events, as a way to make sense of the historic narrative as depicted in the footage. We owe this first level of organisation and contextualisation to the numerous authors of the Daraa archive.

Ghani's idea of the digitized film is particularly useful here, although the Daraa materials were born digital. She notes that digital films are not bound to a 'specific materiality', and can gain the power for wider distribution and consumption: 'digital films can migrate from the archive-as-vault to the archive-as-network. It can be recontextualised, reused, remixed. The physical archive may be dispersed, or even destroyed while the digital archive lives on, copies of copies proliferating across time and space. ${ }^{30}$

But is it a correct assumption that a digital archive is less likely to be destroyed than a physical one? And is the digital really bound to proliferate across time and space?

\section{The anxiety of the digital}

'We were archiving so no one forgets' ${ }^{31}$. Our mapping and analysis of the Daraa archive, and our interviews with one the activists who compiled this material served as an entry point to explore the relation between archival practices and memory. It quickly became apparent to us that one of the main motivations behind compiling the Daraa archive was preservation: to counter forgetfulness, and to safeguard the memory of the people and places from the destructive chaos of the war. 
At the same time, there seems to be a consensus among scholars, that the digital is in fact an unstable source, constantly liable to decay and collapse. For example, Andrew Hoskins argues that in today's media ecology, the relations between remembering and forgetting are defined by a series of "paradoxical states of permanence and obsolescence, of empowerment and loss of control, and of stability and ephemerality. ${ }^{32}$ As such, despite the fact that the promise and persuasiveness of the digital has pushed the limits of memory, and has given remembering a whole new potential, it has also created new risks, ones he refers to as 'the perpetual hauntings of the loss of control' due to the unknowable workings and vulnerabilities of the network. He notes that 'what was once an active memory, a human memory that had to work to sustain a continuity of past - of identity, of place, of relationships - is fundamentally weakened with the shift from reliance to dependency on the search devices of our machine. 33

This same resistance to the promise of the digital is shared by Wendy Chun who considers that while digital media has become an ever-expanding archive that gives the appearance that nothing is lost, it has actually made archives more volatile both in content and in form. Chun explains, that while the digital has been 'heralded as 'saving' analog media from destruction and obscurity ${ }^{34}$, users are blind to its precarity and limitations. She sees in the promise of the digital an actual threat: 'digital media, if it 'saves' anything, does so by transforming storage into memory, by making what decays slowly decay more quickly, by proliferating what it reads. [...] Digital media poses new challenges and opportunities for 'the archive. ${ }^{35}$ She goes as far as considering that new media could actually signify the 'end' of the archives. 
When thought of in the context of our Daraa archive, this 'digital anxiety' means that whatever the wealth of data, testimony, and witness, its jeopardy is apparent in the singular nature of the hard drive that escaped Syria, and the fact that the digital files are not permanent. It is in that sense that we proposed, at the outset of this article, that the Daraa material should maybe be considered as an archive in the making, seeking fixity and grounding.

While mediated, but not able to access broadcast networks, the Daraa footage is condemned to only exist in its perilous physical form - in the hard drive that was smuggled on foot through the Jordanian border, or if to rely on the 'good will' of international corporations such as YouTube to keep activists' channels up and running.

Ironically - or tragically - a copy of the Daraa archive was stolen from one of the present authors' luggage when traveling through Frankfurt airport in 2015. That copy might have been destroyed, or is just sitting somewhere, on someone else's computer, waiting.

\section{Conclusion}

'Yadan Zaatari.mp4' was shot on August 13, 2012. It is 3'20' in length and is filmed in a large canvas tent, rippled by wind. An intensely sunny day is visible outside as is a mesh fence and an array of similar tents all badged UNHCR. We recognise Yadan Drajy; he is sitting on the floor, and is describing in great detail the everyday lives of Syrian refugees in Zaatari. The Zaatari camp is located in Jordan, and is one of the biggest Syrian refugee camps today, with a population of over 80,000 people. Thirteen months after his 'one man protest in Daraa' and his 'I won't leave' promise, Yadan fled Syria and is a refugee in Jordan.

He still lives in Jordan with his wife and son. 

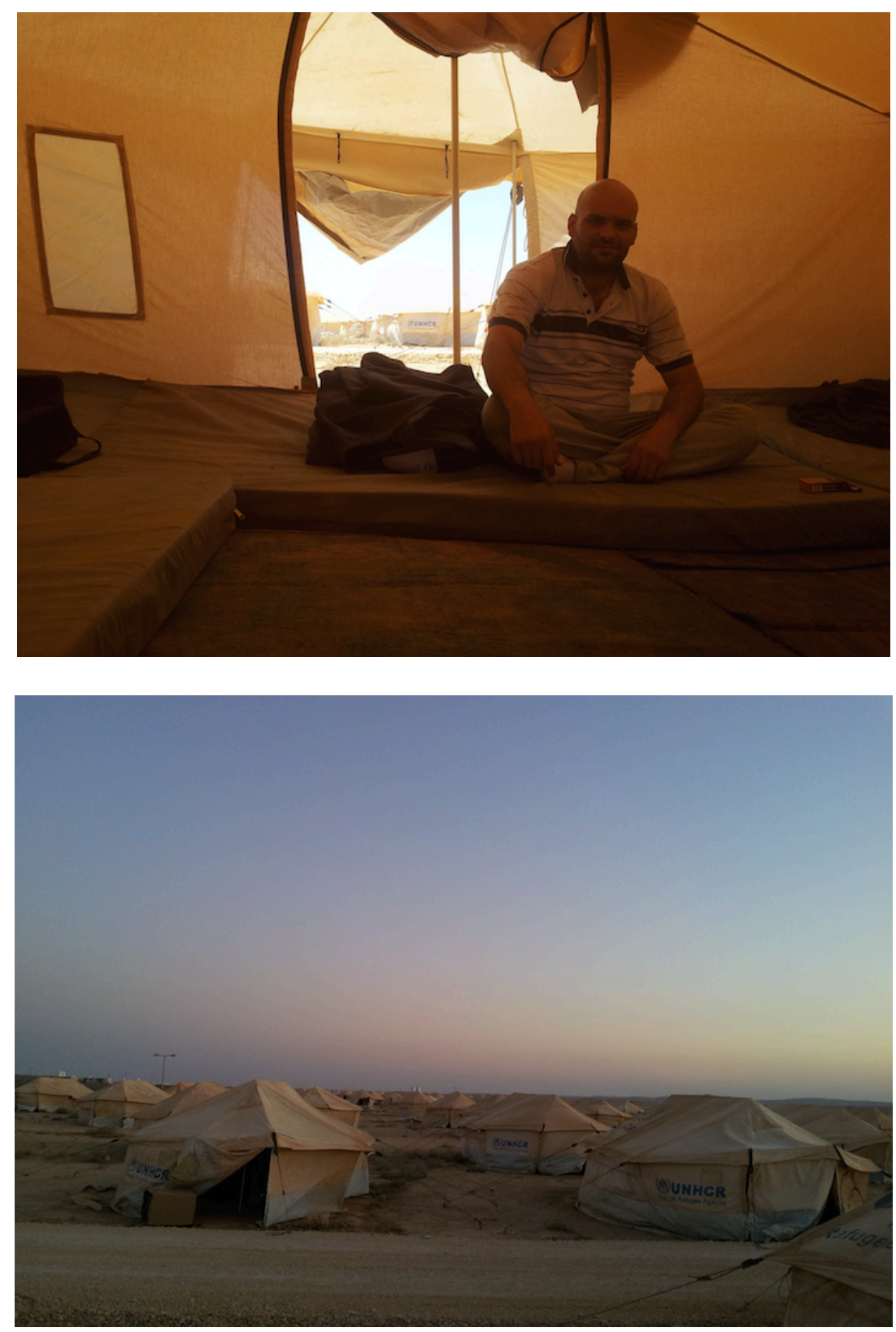

Figure 5: 'Yadan Zaatari', screenshots by the authors

Shortly after he fled to Jordan, Yadan Drajy entrusted his hard drive to two filmmakers to use in the production of a documentary film. By so doing, he gave his archive grounding and sustainability; when another copy of his archive made its way to a research centre in the UK, it acquired yet another form of fixity. 
Following the journey of the Daraa archive from testimony to performance to data - from documenting the Syrian uprising in a similar mode to war reportage, to being used in the making of a film, to becoming empirical data as part of a research project, we argue that these new 'homes' of the Daraa archive are allowing it to become fully formed, through giving it roots and sustainability beyond the affordances of the digital, and all the anxieties of precariousness connected to it.

It might be suitable then to characterise the Daraa material as a particular form of archive; one in the process of becoming. Like the individuals who, along with thousands of others, fled Syria with similar footage, and the form in which it was transported, it might be useful to think of the Daraa material as a 'refugee archive'. In its material status, and in the references of the materials it collects and protects, it alludes to the roots, origins, dislocation, displacement and trauma of a settled population forced to migrate, not in search of a better life, but simply in order to stay alive.

\section{Notes}

1. Wolfgang, 'Aura and Temporality', 5.

2. Sheperd, 'Culture and Evidence', 173.

3. Ibid., 183.

4. Yadan Drajy, interview and translations by the authors, July 2016.

5. Ibid.

6. Foucault, The Archaeology of Knowledge, 129.

7. See note 4 above.

8. Koselleck, Future Past.

9. See note 4 above.

10. Frosh and Pinchevski, Media Witnessing.

11. Andén-Papadopoulos, ‘Journalism and Memory’, 149. 
12. Ricoeur, 'The Hermeneutics of Testimony', 129.

13. Margalit, The Ethics of Memory, 150.

14. See note 8 above.

15. See note 9 above.

16. Farge, The Allure of the Archives, 31.

17. See note 4 above.

18. Farge, The Allure of the Archives, 32.

19. Caswell, Cifor and Ramirez, 'Discover Oneself Existing', 60.

20. Ibid., 62.

21. Ibid., 57.

22. See note 4 above.

23. Caswell, Cifor and Ramirez, 'Discover Oneself Existing', 75.

24. Azoulay, 'Archive', 195.

25. Ibid.

26. Ibid., 198.

27. Cifor and Gililiband, 'Affect and the Archive', 2.

28. See note 4 above.

29. Ghani, 'What We Left Unfinished', 45.

30. Ibid., 54.

31. See note 4 above.

32. Hoskins, 'Archive Me!', 14.

33. Ibid., 15.

34. Chun, Programmed Visions, 137.

35. Ibid., 138.

\section{Bibliography}

Andén-Papadopoulos, Kari. 'Journalism, Memory and the Crowd-Sourced Video Revolution.' In Journalism and Memory, edited by Barbie Zelizer and Keren Tenenboim-Weinblatt, 148-163. London: Palgrave Macmillan, 2014.

Azoulay, Ariella. 'Archive.' In Dissonant Archives, edited by Anthony Downey, 194214. London: I.B. Tauris, 2015. 
Caswell, Michelle, Cifor, Marika, and Ramirez, Mario H. 'To Suddenly Discover Yourself Existing': Uncovering the Impact of Community Archives.' The American Archivist 70, no. 1 (2016): 56-81. doi http://dx.doi.org/10.17723/0360-9081.79.1.56.

Chun, Wendy Hui Kyong. Programmed Visions: Software and Memory. Cambridge: MIT, 2011.

Cifor, Marika, and Gilliland, Anne J. 'Affect and the Archive, Archives and Their Affects: An Introduction to the Special Issue.' Archival Science 16, no. 1 (2016): 1-6. doi: 10.1007/s10502-015-9263-3.

Downey, Anthony, ed. 2015. Dissonant Archives: Contemporary Visual Culture and Competing Narratives in the Middle East (Vol. 1). London: I.B. Tauris, 2015.

Farge, Arlette. The Allure of the Archives. Yale: University Press, 2013.

Foucault, Michel. The Archaeology of Knowledge. London: Tavistock Publications Limited, 1972.

Frosh, Paul, and Pinchevski, Amit, eds. Media witnessing: Testimony in the Age of Mass Communication. London: Palgrave Macmillan, 2009.

Ghani, Marian. 'What We Left Unfinished: The Artist and the Archive.' In Dissonant Archives, edited by Anthony Downey, 43-63. London: I.B. Tauris, 2015.

Hoskins, Andrew. 'Archive Me! Media, Memory, Uncertainty.' In Memory In a Mediated World. Remembrance and Reconstruction. Edited by Hajek, Andrea, Lohmeier, Christine, and Pentzold, Chirstian, 13-35. London: Palgrave Macmillan, 2016. 
Koselleck, R., 2004. Future Past: On the Semantics of Historical Time. Trans by Keith Tribe. New york: Columbia University Press.

Margalit, Avishai. The Ethics of Memory. Cambridge, MA: Harvard University Press, 2002.

Ricoeur, Paul. Essays in Biblical Interpretation. London: SPCK, 1981.

Shepherd, Elizabeth. 'Culture and Evidence: Or What Good are the Archives? Archives and Archivists in Twentieth Century England.' Archival Science 9: 173-185 (2009). doi:10.1007/s10502-009-9077-2.

Wolfgang, Ernst. 'Aura and Temporality: The Insistence of the Archive.' Key-note speech on occasion of the workshop The Anarchival Impulse in the Uses of the Image in Contemporary Art, Museum of Contemporary Art, Barcelona, October $24,2012$. 